Research Article

\title{
Investigation of the Optimization of Unloading Mining Scheme in Large Deep Deposit Based on Vague Set Theory and Its Application
}

\author{
Jia Sheng $\mathbb{D},{ }^{1,2}$ Wen Wan $\mathbb{D}^{1},{ }^{1}$ Dongrui Liu $\mathbb{D}^{2},{ }^{2}$ Feifei Jiang $\mathbb{D},{ }^{3}$ Xiangdong Li $\mathbb{D}^{2}{ }^{2}$ \\ and Haiyun Zhang $\mathbb{D}^{2}$ \\ ${ }^{1}$ School of Resource and Environment and Safety Engineering, Hunan University of Science and Technology, \\ Xiangtan 411201, China \\ ${ }^{2}$ National Engineering Research Center for Metal Mining, Changsha Institute of Mining Research Co., Ltd., \\ Changsha 410012, China \\ ${ }^{3}$ State Key Laboratory of Geomechanics and Geotechnical Engineering, Institute of Rock and Soil Mechanics, \\ Chinese Academy of Sciences, Wuhan 430071, China
}

Correspondence should be addressed to Jia Sheng; shengjia001@163.com

Received 14 October 2020; Revised 11 December 2020; Accepted 21 January 2021; Published 9 February 2021

Academic Editor: Xun Xi

Copyright (c) 2021 Jia Sheng et al. This is an open access article distributed under the Creative Commons Attribution License, which permits unrestricted use, distribution, and reproduction in any medium, provided the original work is properly cited.

With the development of shallow surface mineral resources in metal mines, it is gradually turning to the stage of deep mining. According to the current mining depth and the average annual depth, during the period of "14th Five-Year Plan," one-third of the underground metal mines will reach or exceed the mining depth of $1,000 \mathrm{~m}$, with the deepest being $2,000 \mathrm{~m}$. In the stage of deep mining, mines will face the conditions of high stress, high temperature, high well depth, and strong mining disturbance, which will greatly increase the difficulty of large-scale deep mining. Among them, the high ground stress environment is the principal problem of many technical problems in deep mining. The selection of mining method has become a prerequisite for solving the problem of efficient and safe mining of deep deposits. In this paper, the vague set theory was introduced into the selection of mining methods and a vague set model for deep unloading mining schemes was established. Taking the Jinchuan No. 2 mining area as the engineering background, four unloading schemes for deep mining were proposed, and the Vague set model was used for optimization. It is concluded that the mining approach with large-section unloading is the optimal unloading mining plan. The application shows that it has the advantages of high unloading efficiency, large production capacity, and low loss index. It has been fully promoted in the deep mining of the mining area. It is feasible and effective to use the vague set theory in the selection of deep unloading mining schemes, which provides a proper approach in the selection of deep unloading mining schemes.

\section{Introduction}

For mining companies, the proper mining method is the key factor in determining their survival and development. How to select the optimum mining method based on the actual situation is an important problem [1-4]. With the gradual advancement of mining to the deep, affected by the highstress environment $[5,6]$, deep mining is facing problems such as low efficiency, insecurity, and high cost, and traditional mining models are difficult to adapt to the deep deposit mining [7-9]. How to choose the optimum mining method considering deep high-stress conditions to ensure mining efficiency, reduce production risks, and improve recovery efficiency is a technical problem for the mining engineers and technicians, which needs to be urgently solved.

In recent years, with the development of technology and theories, many researchers have put forward methods and theories for mining plan selection considering varied factors $[10,11]$. Until recently, it is more typical to use fuzzy mathematics theory to optimize mining methods. On this basis, methods and theories such as the gray correlation method, analytic hierarchy process, catastrophe optimization theory, and approximation to optimal solution theory 
have been developed, as well as the selection of mining methods based on artificial intelligence algorithms proposed in recent years with the development of artificial intelligence algorithms [12]. However, the methods mentioned above are all based on mathematical calculations. Compared with the traditional engineering analogy method, it has the advantages of strong objectivity and more accurate results. Because there are many factors that affect the selection of mining methods in actual application. It is necessary to select the appropriate method to optimize the mining method according to the type of conditions, that is, there are certain limitations in all aspects, and there is no unified method of mining method selection [13-15]. The most important factor affecting the accuracy of the mining method selection method is how to objectively quantify the uncertainty of fuzzy sets in mining method selection.

Vague set theory was proposed by Gau and Buehre [16] to solve the shortcomings of fuzzy set theory in practical applications and to study mathematical methods that are close to the way of thinking of human behavior. The objective is to help decision makers make the most accurate judgments on the fuzzy factors encountered in actual decision-making. Compared with other methods, the vague sets consider three factors: true membership, false membership, and hesitation. It is more accurate and flexible in expressing vagueness and uncertainty of information than traditional fuzzy sets. Many intelligent systems, such as fuzzy expert decision systems, data mining, and fuzzy recognition, have been widely used [17].

Considering the importance of mining method selection and the ambiguity and uncertainty of the process, this work attempts to introduce the vague sets into the selection of mining methods. We use the advantages of the theory in fuzzy decision-making to uniformly quantify the various parameters that affect the choice of mining schemes. This work will help improve the accuracy of program selection and provide a new idea for mining method selection.

\section{Theory and Background of Vague Sets}

According to [17], let $X$ be a point or an object space in which any element is represented by $x$, and a vague set $V$ in $X$ is represented by a true membership function $t_{v}$ and a false membership function $f_{v} . t_{v}(x)$ is the lower bound of the membership degree of $x$ derived from the evidence supporting $x$, and $f_{v}(x)$ is the lower bound of the negative membership degree of $x$ derived from the evidence against $x$, $t_{v}(x)$ and $f_{v}(x)$. A real number in the interval $[0,1]$ is connected to each point in $X$. According to the above definition, in the vague set, a subspace $\left[t_{v}(x), 1-f_{v}(x)\right]$ on $[0,1]$ is used to limit the membership of $x$, where $t_{v}(x)$ represents the true membership function of vague set $V$, which represents the necessary degree of evidence supporting $x \in \mathrm{X}$. $\left(1-f_{v}(x)\right)$ represents the possibility of evidence against $x \in \mathrm{X}$. In this way, the difference $\left(1-t_{v}(x)-f_{v}\right.$ $(x))$ can be used to express the uncertainty of $x$. If the difference is small, it means that we can know $x$ very accurately; if the difference is large, it means that very little about $x$; if $1-f_{v}(x)=t_{v}(x)$, it means that we know $x$ exactly; then, the vague set is the standard fuzzy set; if $\left(1-f_{v}(x)\right)$ and $t_{v}(x)$ is 1 or 0 at the same time, it depends on whether $x$ belongs to or not to the vague set. At this time, the information about $x$ is an accurate value, which means that the vague set is a normal set [17].

When $X$ is continuous, a vague set can be expressed as

$$
V=\frac{\int_{x}\left[t_{v}(x), 1-f_{v}(x)\right]}{x}, \quad x \in X .
$$

When $X$ is discrete, a vague set can be expressed as

$$
V=\frac{\sum_{i=1}^{n}\left[t_{v}\left(x_{i}\right), 1-f_{v}\left(x_{i}\right)\right]}{x_{i}}, \quad x_{i} \in X .
$$

The vague set is an extension of a fuzzy set and ordinary set, and its definition is consistent with them. Multiobjective fuzzy decision-making is that the decision maker must make the best choice under the constraints of all the set of constraints, that is, select the objective that best meets these constraints from a set of multiple objectives. Suppose the decision objective set $M=\left\{M_{1}, M_{2}, \ldots, M_{n}\right\}, D=\left\{D_{1}, D_{2}, \ldots\right.$, $\left.D_{n}\right\}$ is the set of constraint conditions, assuming that the vague set represents the characteristics of the target $M_{\mathrm{i}}$ under the constraint condition $D$ as

$$
\begin{aligned}
M_{i}= & \left\{\left(D_{1},\left[t_{i 1}, 1-f_{i 1}\right]\right),\left(D_{2},\left[t_{i 2}, 1-f_{i 2}\right]\right),\right. \\
& \left.\cdots\left(D_{n},\left[t_{i n}, 1-f_{\text {in }}\right]\right)\right\},
\end{aligned}
$$

where $t_{i j}$ is the degree to which the decision objective $\mathrm{Mi}$ satisfies the constraint condition $D_{\mathrm{j}}$ and $f_{i j}$ is the degree to which the decision objective $M_{i}$ does not satisfy the constraint condition $D_{j}$. Assume that the decision maker wants to select an objective in the decision objective set $M$ while satisfying the constraint conditions $D_{j}, D_{k}, \ldots, D_{p}$ or satisfy the constraint $D_{s}$. That is, the request of the decision maker is $D_{j}$ and $D_{k}$ and $\ldots$ and $D_{p}$ or $D_{s}$. The degree to which the decision objective $M_{i}$ meets or does not meet the requirements is determined by the evaluation function $F$ :

$$
\begin{aligned}
F\left(M_{i}\right)= & \left(\left[t_{i j}, 1-f\right]_{i j} \wedge\left[t_{i k}, 1-f_{i k}\right] \wedge \cdots \wedge\left[t_{i p}, 1-f_{i p}\right]\right) \\
& \cdot \vee\left[t_{i s}, 1-f\right]_{i s}=\left[t_{M_{i}}, 1-f_{M_{i}}\right]
\end{aligned}
$$

where $\wedge$ and $\vee$ represent the operation of the intersection and union of vague values; the values of $t_{M i}$ and $\left(1-f_{M i}\right)$ are shown in equations (5) and (6):

$$
\begin{aligned}
t_{M_{i}} & =\max \left(\min \left(t_{i j}, t_{i k}, \cdots t_{i p}\right), t_{i s}\right), \\
1-f_{M_{i}} & =\max \left(\min \left(1-f_{i j}, 1-f_{i k}, \cdots 1-f_{i p}\right), 1-f_{i s}\right) .
\end{aligned}
$$

For the evaluation value $F\left(M_{i}\right)=\left[t_{M i}, 1-f_{M i}\right]$, the voting model is used to explain that the votes in favor of the vote are $t_{M i}$, those who do not vote in favor of the vote are $1-f_{M i}$, and the proportion of abstentions is $\alpha=1-t_{M_{i}}-f_{M_{i}}$. Suppose $x=\left[t_{x}, 1-f_{x}\right]$ is a vague value on the universe $V$; then, the 
accuracy of $x$ is represented by the scoring function $Q$, which is expressed as

$$
Q(x)=t_{x}+f_{x}+\lambda\left[\frac{1-t_{x}-f_{x}}{2}\right], \quad Q(x) \in[-1,1] .
$$

Then,

$$
\begin{gathered}
Q\left(F\left(M_{i}\right)\right)=t_{M_{i}}+f_{M_{i}}+\lambda\left[\frac{1-t_{M_{i}}-f_{M_{i}}}{2}\right], \\
\cdot Q\left(F\left(M_{i}\right)\right) \in[-1,1],
\end{gathered}
$$

where $\lambda$ is the degree of neutrality, which represents the degree of neutrality of the persons who abstained from voting, and $\lambda\left[\left(1-t_{x}-f_{x}\right) / 2\right]$ is the probability that the neutral persons vote in favor of $1 / 2$.

\section{Vague Model considering Deep Unloading in Mining Selection}

For the high-stress mining environment, some scholars have put forward many unloading mining theories, such as the pressure arch theory, support pressure theory, maximum horizontal ground stress theory and partition mining, slab theory, pressure relief support theory, and axial deformation theory $[18,19]$. Based on these theories, the majority of engineers have used similar simulations, numerical simulations, and in-situ tests to conduct analysis and research, carried out on-site practice, and achieved certain application effects [20-22]. According to the vague theory, the target set is the deep unloading mining plan, and the constraint set is mining cost, ore production capacity, mining-to-cut ratio, loss ratio, dilution ratio, unloading capacity, and other six indicators. The model is constructed as follows:

(1) Apply numerical simulation to calculate the unloading capacity of the scheme.

In this section, the FLAC3D code, which is popular in mechanical analysis in underground mining, is used to calculate and analyze the average stress value of each scheme. The larger the value is, the worse the unloading capacity is. After that, it is normalized to reflect the actual unloading capacity of each plan.

(2) Determine the weight between various indicators.

The coefficient of the variation method was used to determine the weight of the five indicators. That is, first normalize the mining cost, ore production capacity, and mining-cut ratio; then, the constraint indicators of each plan was used to construct a constraint matrix, calculate the mean, and standard deviation of the matrix, and finally determine the coefficient of variation and the weight of each index in the matrix.

(3) Determine the vague value of each index.

According to the determined weight, delimit the production capacity $(K)$ and unloading capacity $(X)$ of the ore block as $t_{\mathrm{i}}$ and the mining cost $(C)$, the mining-cut ratio $(Q)$, the dilution ratio $(H)$, and the loss ratio $(S)$ as $f_{\mathrm{i}}$; the calculation formula is as follows:

$$
\begin{aligned}
& t_{i}=w_{k} K^{\prime} \times(1-H-S)+w_{x} X, \\
& f_{i}=w_{h} H+w_{s} S+w_{c} C^{\prime}+w_{q} Q^{\prime},
\end{aligned}
$$

where $w_{i}$ is the weight of the constraint and $i$ represents each constraint index. The reason for determining these components is they have correlations, either positive or negative, with the value of vague. The weight of each constraint index is calculated and determined by the analytic hierarchy process.

(4) Calculate the final score of each unloading mining plan.

After determining the support $t_{i}$ and nonsupport $f_{i}$ of the unloading mining plan, equations (7) and (8) are used to calculate the score of each unloading mining plan.

(5) According to the final score ranking of each unloading plan, determine the optimal unloading mining plan.

After obtaining the scores of various unloading mining schemes, they are sorted, and the one with the highest score is the optimal scheme. If there are schemes with the same score, the one with the smaller average stress value of the historical recovery is taken.

\section{Engineering Application}

4.1. Background of the Engineering Case. Jinchuan Group Co., Ltd. is China's largest nickel ore resource production base. The output of the second mining area accounts for more than two-thirds. The ore production capacity has exceeded 4.3 million $t / a$. It is one of the largest nonferrous metal underground mines in China with the largest annual production capacity, mechanization, and modernization and the highest degree of filling mining method mines. At present, the mechanized panel downward-layered horizontal approach cemented filling mining method is mainly used to realize the continuous mining of large areas in multiple middle sections. The second mining area is about to fully transitioned to the stage of resource recovery of the $1000 \mathrm{~m}$ middle horizontal pillar, and it mainly faces many mining technical problems. The joints and fissures of the ore rock are developed, the stability of the surrounding rock is poor, the fissure water is more abundant than the upper part, the pressure of the stope is severe, and the deformation is severe and difficult to control. The in-situ stress is large, mainly including the rock layer's own weight stress in the vertical direction and the tectonic stress in the approximately horizontal direction. The horizontal stress is 1.69 to 2.27 


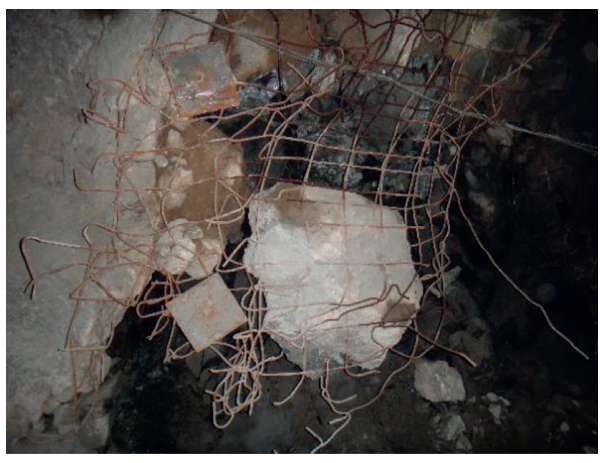

(a)

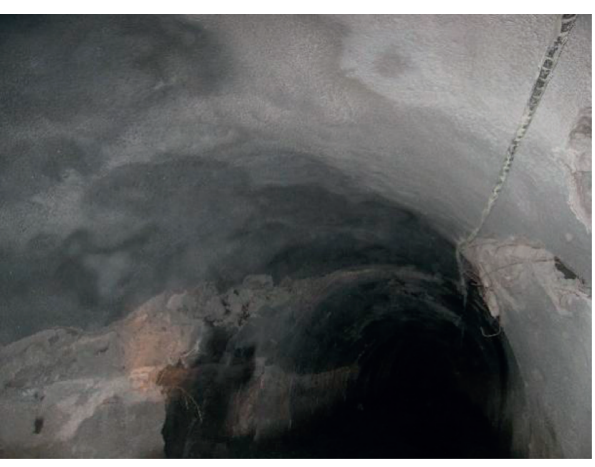

(b)

Figure 1: Ground pressure deformation and failure map of Jinchuan No. 2 mining area. (a) Failure of the supporting system. (b) Failure of the roadway.
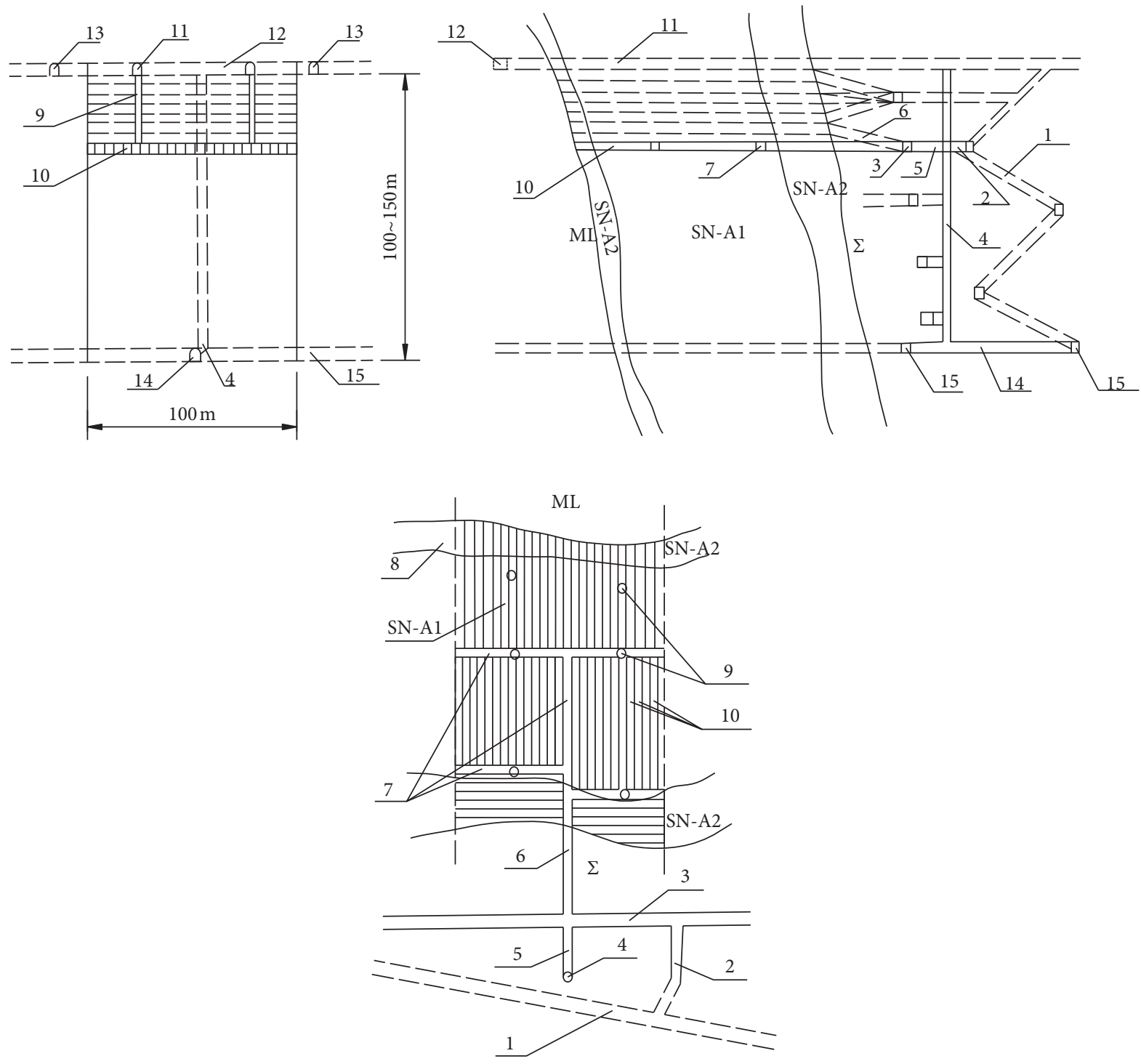

1. Ramp

2. Access road

3. Section road

4. Orepass

5. Orepass contact road
6. Access road

7. Layer road

8. Footwall orebody

9. Air roadway

10. Roadway
11. Air roadway across orebody

12. Air roadway

13. Haul road

14. Roadway

15. Haul road

FIgURE 2: Design of the mechanized panel downward mining approach. 

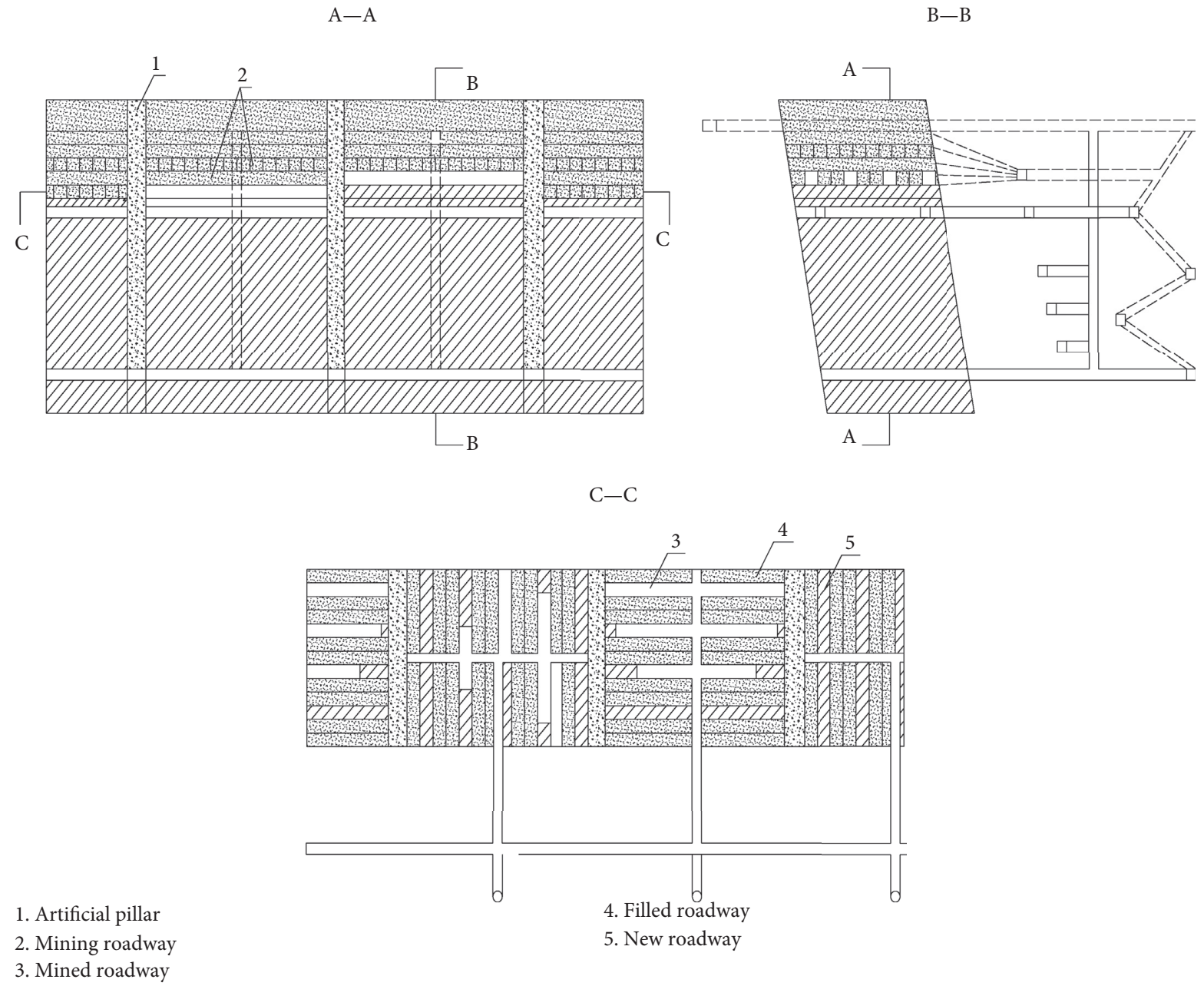

FIGURE 3: Design of the partitioned unloading panel large-section downward mining approach.

times of the dead weight stress, and its maximum value is $50 \mathrm{MPa}$. The rock mass has obvious creep characteristics, such as roof fall, slabs, floor heave, and roadway crosssection reduction, as shown in Figure 1.

4.2. Schemes of Unloading Mining. According to the actual situation of Jinchuan No. 2 mining area, we developed four technically feasible mining planes including a mechanized panel downward mining approach, a partitioned unloading panel large-section downward mining approach, a partitioned unloading panel downward segmented filling, and a mining approach with large-section unloading access in the zone. Each option is briefly described as follows.

4.2.1. Scheme I: Mechanized Panel Downward Mining Approach. The height of the middle section of the ore body mining is $100-150 \mathrm{~m}$, and the height of the section is $20 \mathrm{~m}$, as shown in Figure 2. The approach (width $\times$ height is $4.0 \mathrm{~m} \times 4.0 \mathrm{~m}$ ) is adopted for mining. It is divided into one panel along the strike of $130-150 \mathrm{~m}$, starting from the upper middle section level and going down. The layered approach is cemented and filled and recovered to the level of the lower middle section, and the layers are alternately arranged in a mesh pattern, that is, if the sectioned approach is arranged along the direction of the ore body, the lower section will be arranged vertically, and vice versa.

4.2.2. Scheme II: Partitioned Unloading Panel Large-Section Downward Mining Approach. The height of the middle section of ore body mining is $100 \sim 150 \mathrm{~m}$, and the height of sections is $20 \mathrm{~m}$, as shown in Figure 3. The large-section approach (width $\times$ height is $4.0 \times 4.0 \mathrm{~m}$ ) is adopted for mining, and the unloading project is arranged along the strike at $130-150 \mathrm{~m}$, starting from the upper middle section level. The level of the lower middle section is connected by the layered approach until the cement filling and recovery to the level of the lower middle section. The lowering operation level is about $20 \mathrm{~m}$ ahead of the normal mining layered level. If the section approach is arranged along the direction of the ore body, it will be divided down. The segments are arranged vertically and vice versa. 
$\mathrm{A}-\mathrm{A}$

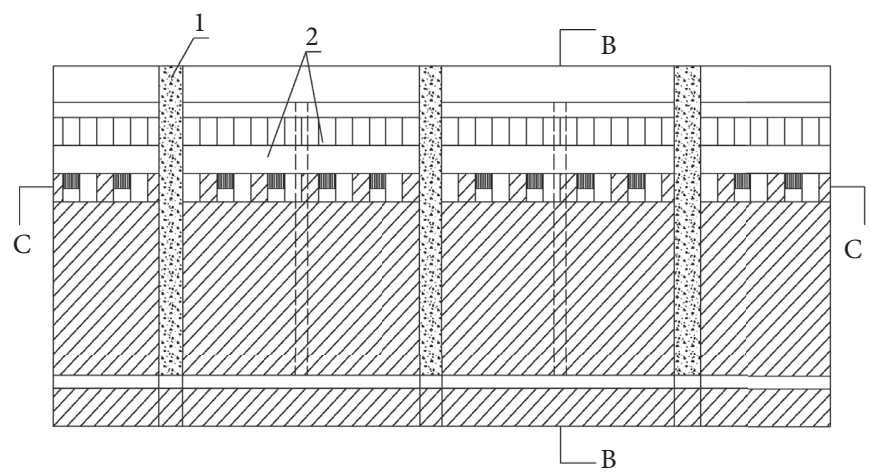

$\mathrm{B}-\mathrm{B}$

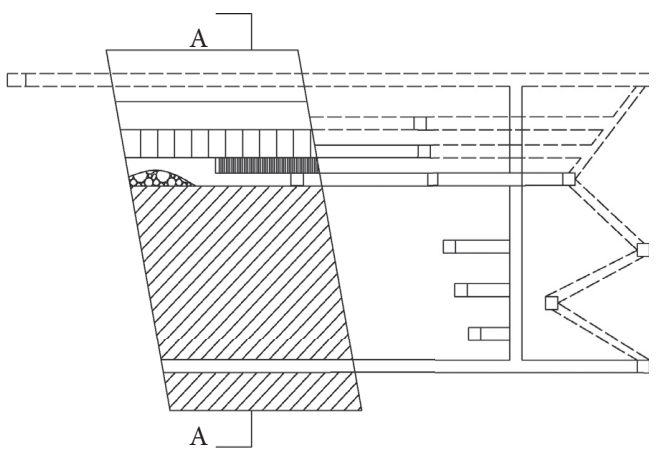

$\mathrm{C}-\mathrm{C}$

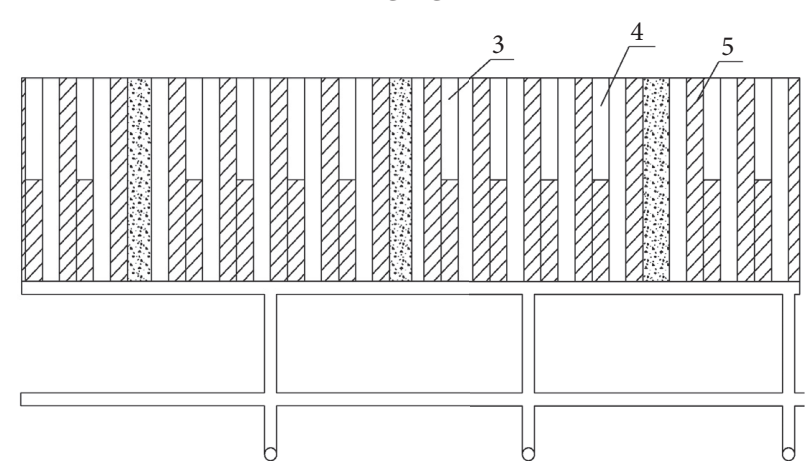

1. Artificial pillar

2. Mining roadway

3. Mined roadway
4. Filled roadway

5. New roadway

FIGURE 4: Scheme of partitioned unloading panel downward segmented filling approach.

4.2.3. Scheme III: Partitioned Unloading Panel Downward Segmented Filling Approach. The height of the middle section of the ore body mining is $100-150 \mathrm{~m}$. The height of the section is $20 \mathrm{~m}$, as shown in Figure 4. A panel is arranged along the direction of the ore body $130-150 \mathrm{~m}$. The lower section is vertical to the direction of the ore body. The panel area is divided into a number of vertical mining filling vertical strips every $5 \mathrm{~m}$. The bottom of the vertical strips is a mediumdeep hole rock drilling roadway with a width of $5 \mathrm{~m}$ and a height of $4 \mathrm{~m}$. The vertical strips are filled with step-by-step interval stope, and the stoping method of interval 1-by-1 can be used, that is, No. 1 , No. 3 , No. 5 , ... roadways are taken. Then, the cementation is filled in, and then, excavate the No. 2 , No. 4, and No. 6, roadways and mine the ores using the medium and deep hole method.

4.2.4. Scheme IV: Mining Approach with Large-Section Unloading Access. The height of the middle section of the ore body mining is $100-150 \mathrm{~m}$, and the section height is $20 \mathrm{~m}$, as shown in Figure 5. The ore body is divided into layers every $5 \mathrm{~m}$ from top to bottom. At each layer level, the layered roadway is firstly driven along the periphery of the ore body as workers, ventilation, and haulageway. The roadways are supported by concrete for the first unloading. During mining, the roadway is firstly driven along the periphery of the panel, and the horizontal stress from any direction is unloaded for the second time. The roadway will be cemented and filled after the stratified mining is completed. After unloading the subdivision layer of the pan, a large-section approach (width $\times$ height is $5.0 \times 4.5 \mathrm{~m}$ ) is adopted for stope.

4.3. Parameters of the Model. For the four proposed unloading mining schemes, FLAC3D is used for modeling and analysis, and the maximum principal stress before and after unloading and the range and degree of stress concentration are calculated and compared. The middle section of the mining area Section \#1000 is selected as the research section, the simulated excavation level is 1058 segments, and the model size is $720 \mathrm{~m} \times 600 \mathrm{~m} \times 180 \mathrm{~m}$. Since Jinchuan adopts an 

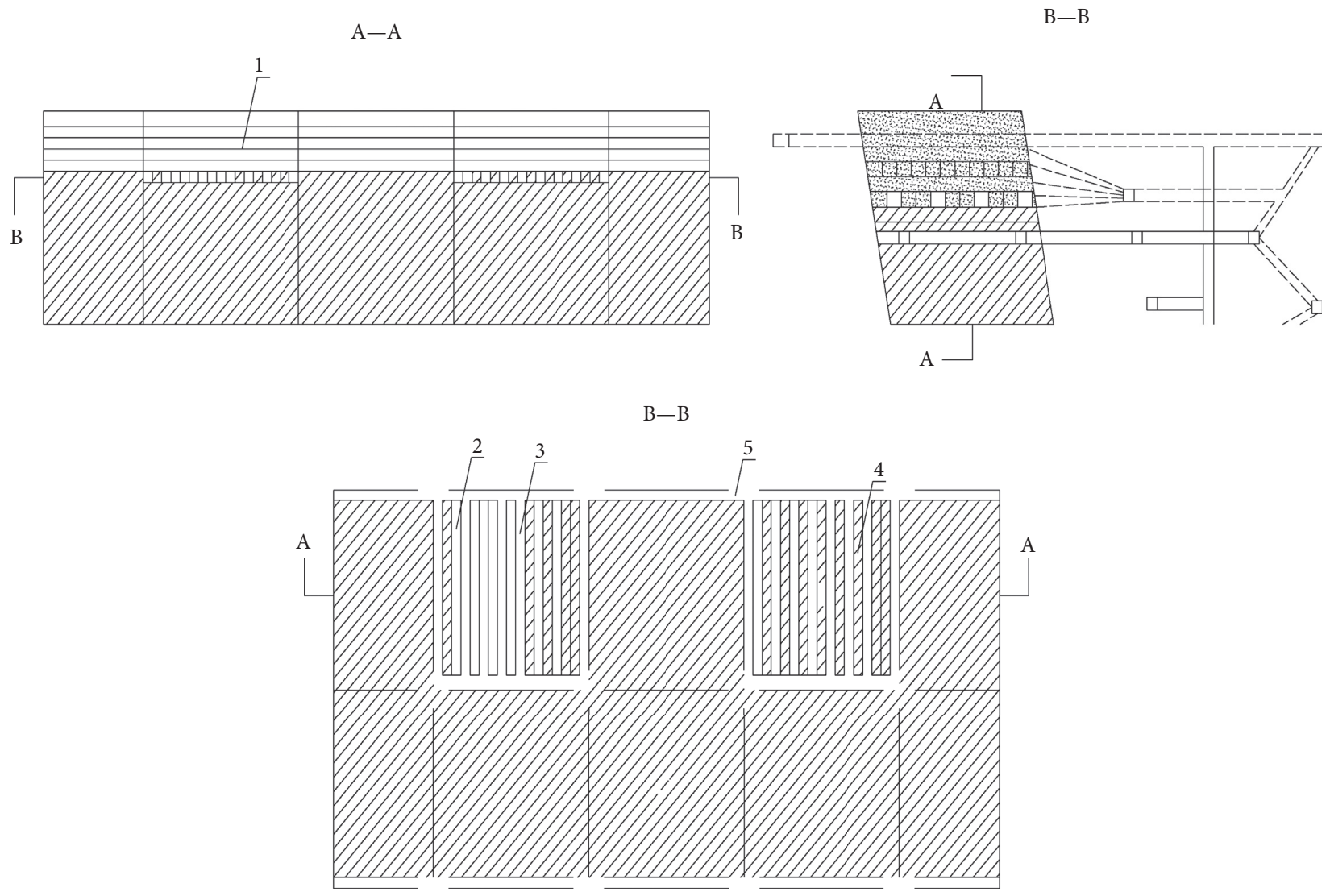

1. Mined area

2. Mined filling entrance

3. Mined unfilled entrance
4. Virgin mining entrance

5. Roadway between layers

FIgURE 5: The mining approach with large-section unloading access. underhand cut-and-fill mining method $[23,24]$, the roof of the ore body is a filling body, as shown in Figure 6. The surrounding rock parameters are selected with reference to $\mathrm{Ta}-$ ble 1 . All the parameters of both the rock and filling materials are obtained according to the experiment reports in the rock lab. The size of the model was set according to the excavation, which is about 2-5 times of the openings. The surrounding gradient stress was applied and the bottom face was fixed.

Numerical simulation was carried out according to the mining steps of the four schemes, and the mining disturbance of a panel is selected as the research object. The maximum principal stress distribution of the four schemes after mining a segment is shown in Figures 7 and 8 . According to the maximum principal stress distribution cloud map after mining a subsection according to the four schemes, it can be found that the stress concentration area is mainly distributed at the bottom plate on both sides of the excavation area. After the stoping and backfilling of subsection is completed, the stress distribution is not much different. However, through the stress changes of the backfill monitoring points, it is found that the stress change history of the four plans in the historical mining process is quite different. As listed in Table 2, the average stresses of the four options of historical recovery are $58.28 \mathrm{MPa}, 54.25 \mathrm{MPa}$, 80.50 $\mathrm{MPa}$, and $38.63 \mathrm{MPa}$, respectively. From the perspective of mining stability, stable stress changes are more conducive to the stability of rock formations and backfills. Therefore, from the analysis of mining stability, Scheme IV should be the optimum approach for the mining area.

According to the description of the above unloading mining plan, the production capacity, mining-cut ratio, dilution ratio, loss ratio, mining cost, and other indicators of the ore block are calculated. The results are shown in Table 3. It can be seen from Table 3 that the panel production capacity of Scheme III is the largest and Scheme I is the smallest; the production cost of Scheme IV is the highest, and Scheme III is the smallest; the pick-to-cut ratio is the largest in scheme II and scheme I is the smallest; the dilution loss ratio is controlled at about 5\%, the dilution loss ratio of scheme three is the largest, the loss ratio of scheme IV and scheme I are the 


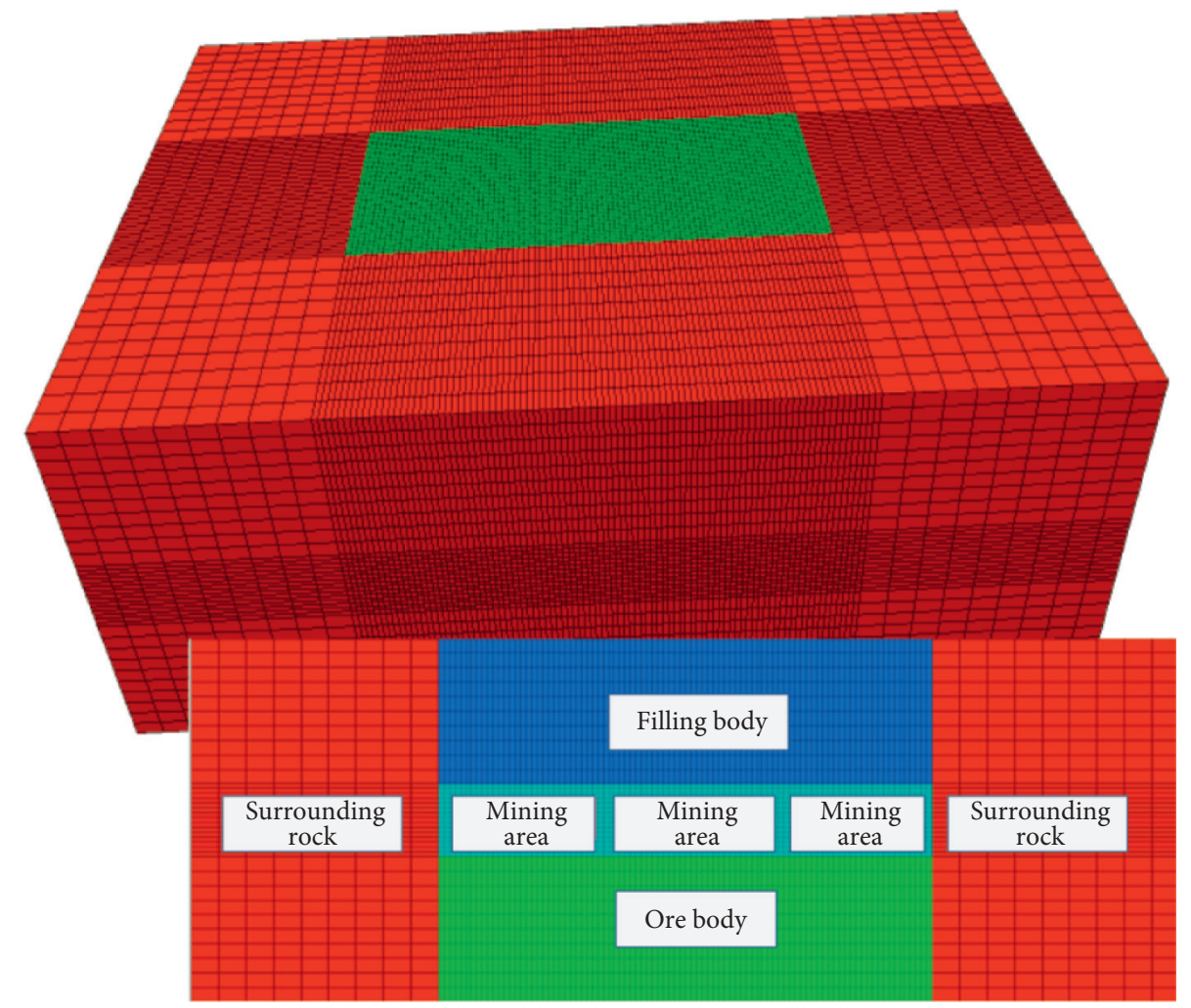

Zone

Color: Group Any

2
3
4

Figure 6: The numerical model of the mining area Section \#1000.

TABle 1: Mechanical parameters of the model.

\begin{tabular}{|c|c|c|c|c|c|c|c|c|c|c|}
\hline Type & $\begin{array}{l}\text { Density } \\
\left(\mathrm{kg} / \mathrm{m}^{3}\right)\end{array}$ & $\begin{array}{c}\text { UCS } \\
(\mathrm{MPa})\end{array}$ & $\begin{array}{c}\text { UCS } \\
(\mathrm{MPa})\end{array}$ & $\begin{array}{c}\text { Tensile } \\
\text { strength } \\
(\mathrm{MPa})\end{array}$ & $\begin{array}{c}\text { Cohesion } \\
(\mathrm{MPa})\end{array}$ & $\begin{array}{l}\text { Friction } \\
\text { angle }\left({ }^{\circ}\right)\end{array}$ & $\begin{array}{c}\text { Elastic } \\
\text { modulus } \\
(\mathrm{GPa})\end{array}$ & $\begin{array}{l}\text { Poisson's } \\
\text { ratio }\end{array}$ & $\begin{array}{c}\text { Bulk } \\
\text { modulus } \\
(\mathrm{GPa})\end{array}$ & $\begin{array}{c}\text { Shear } \\
\text { modulus } \\
(\mathrm{GPa})\end{array}$ \\
\hline $\begin{array}{l}\text { Surrounding } \\
\text { rock }\end{array}$ & 3000 & 39.19 & 39.19 & 1.72 & 2.10 & 36.19 & 15.89 & 0.25 & 8.63 & 2.88 \\
\hline Ore body & 3200 & 22.24 & 22.24 & 0.18 & 1.09 & 38.45 & 2.99 & 0.26 & 1.96 & 0.62 \\
\hline $\begin{array}{l}\text { Filling } \\
\text { material }\end{array}$ & 2800 & 5.23 & 5.23 & 0.50 & 0.76 & 36.60 & 0.81 & 0.32 & 0.87 & 0.57 \\
\hline
\end{tabular}

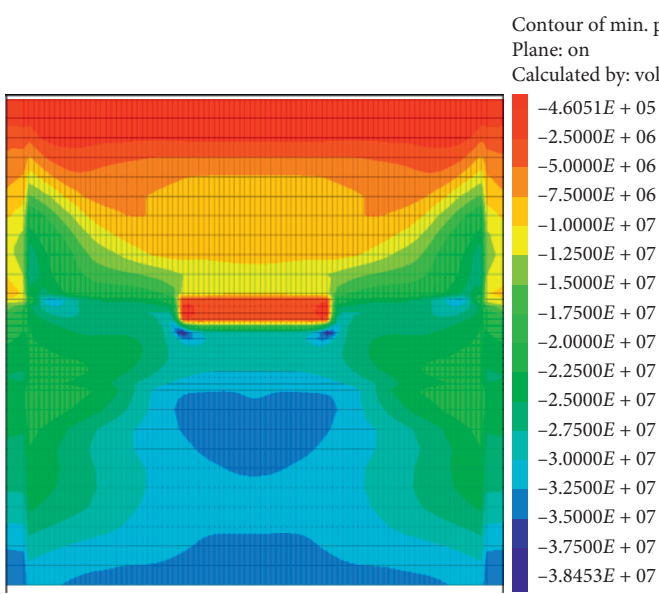

(a)

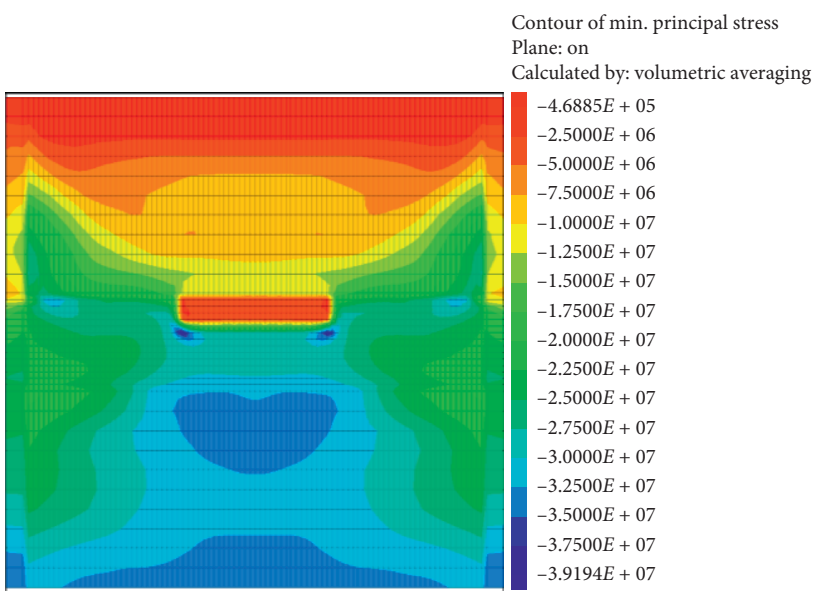

(b)

Figure 7: Continued. 


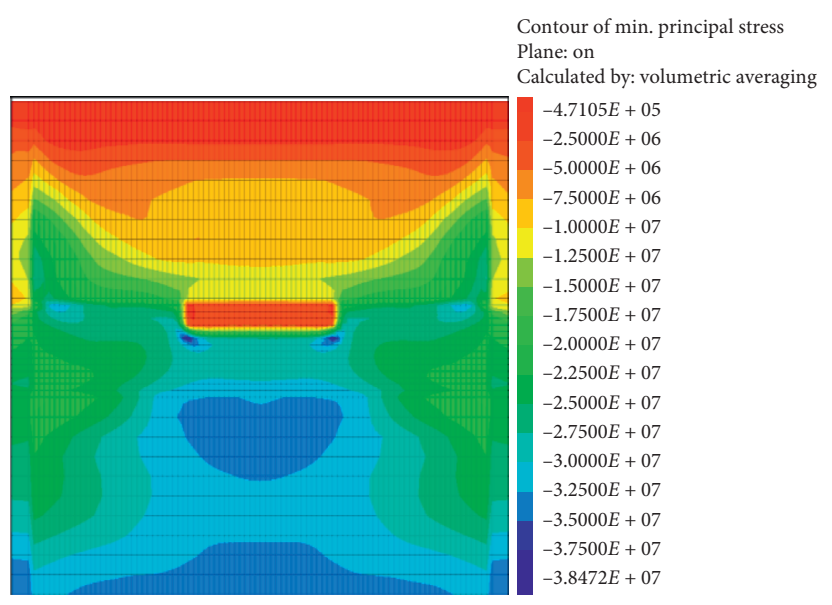

(c)

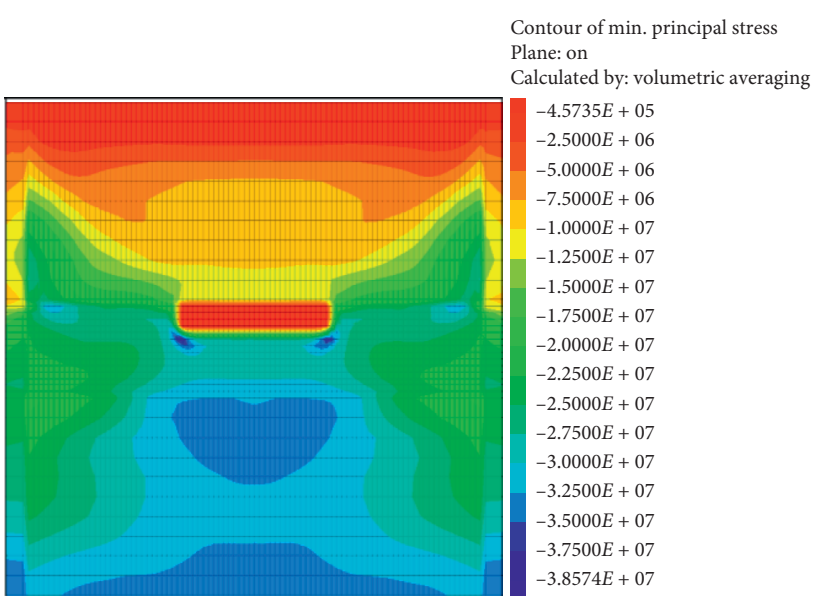

(d)

FIGURE 7: The maximum principal stress distribution cloud diagram of the four schemes (the contour of min. principal stress shown in FLAC code is the max. principal stress). (a) Scheme (I). (b) Scheme II. (c) Scheme III. (d) Scheme IV.

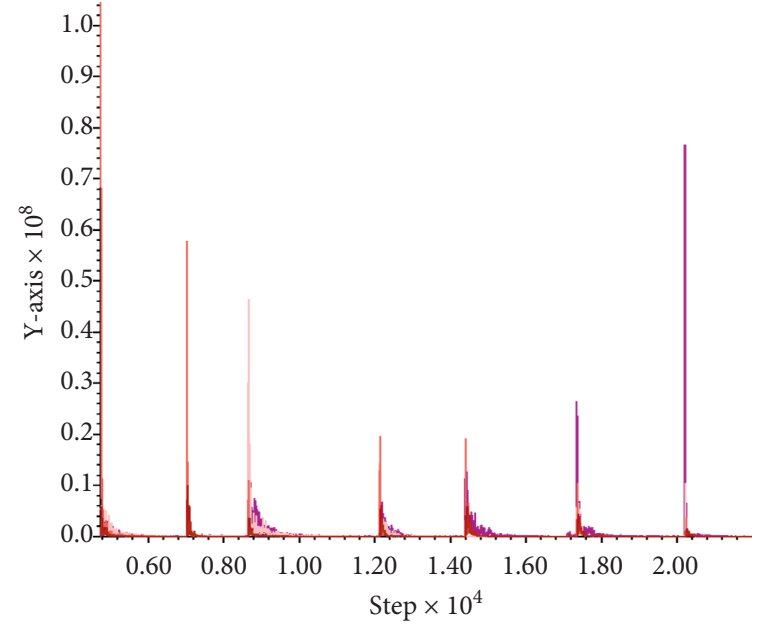

History

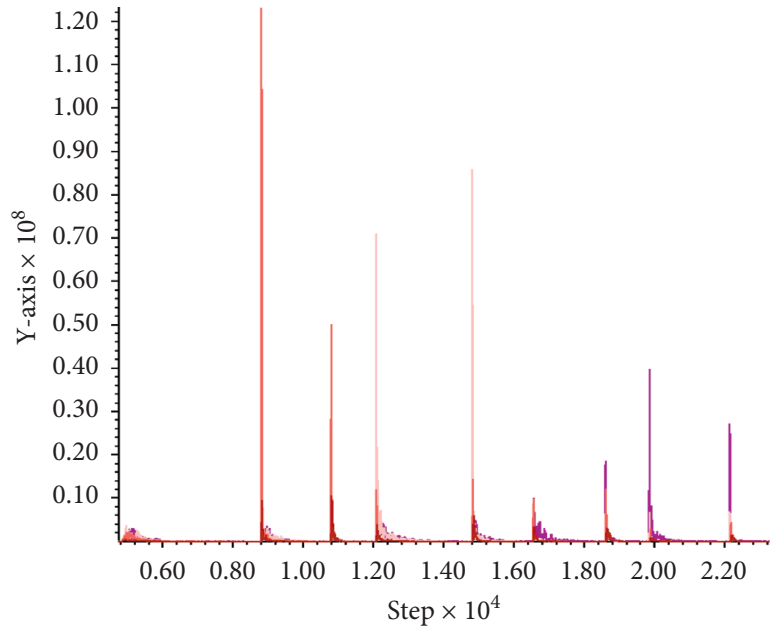

History

(a)

Figure 8: Continued. 


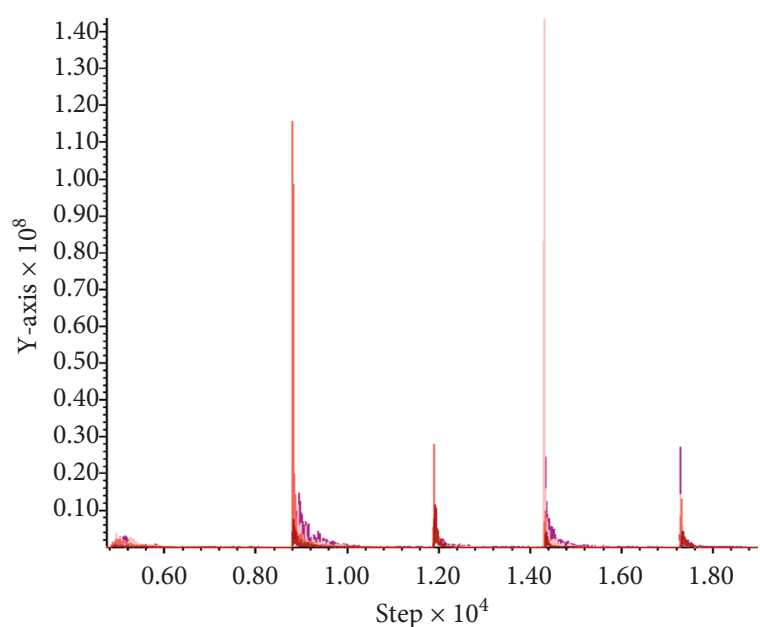

History

(c)

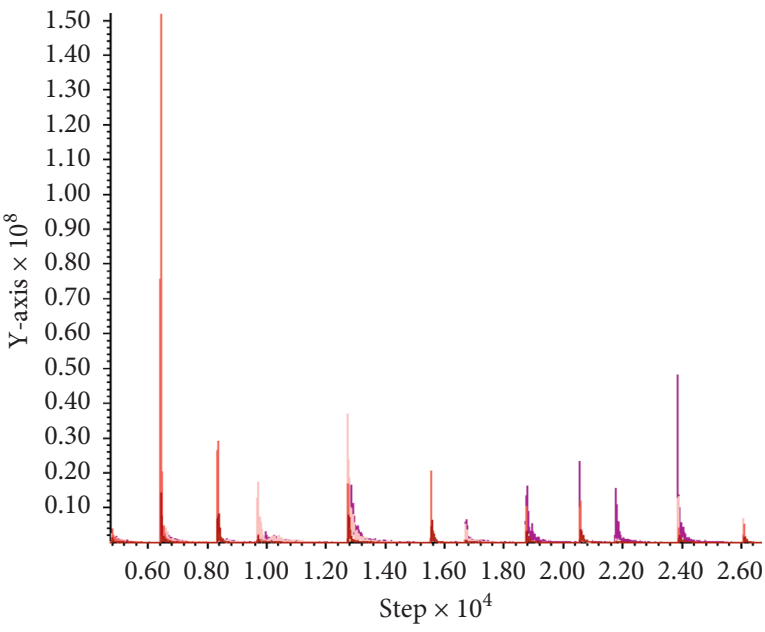

History

_ 27 force magnitude of gp 18884

28 force magnitude of gp 21726

_ 29 force magnitude of gp 2519

_ 30 force magnitude of gp 83459

_ 31 force magnitude of gp 83508

- 32 force magnitude of gp 83508

vs. Step

(d)

FIGURE 8: The stress changes at the monitoring points of the roof fillings of the four schemes. (a) Scheme (I) (b) Scheme II. (c) Scheme III. (d) Scheme IV.

TABLE 2: Comparison of the unloading capacity of four schemes.

\begin{tabular}{lcr}
\hline Scheme & Maximum stress (MPa) & Normalization \\
\hline I & 58.28 & 0.58 \\
II & 54.25 & 0.66 \\
III & 80.50 & 0.10 \\
IV & 38.63 & 1.00 \\
\hline
\end{tabular}

TABLE 3: Technical and economic indicators.

\begin{tabular}{lccccc}
\hline Schemes & $\begin{array}{c}\text { Production } \\
\text { capacity } \\
(\mathrm{t} / \mathrm{d})\end{array}$ & $\begin{array}{c}\text { Cost } \\
\text { (Yuan/t) }\end{array}$ & Ratio of mined tonnage to development (m/kt) & Dilution ratio (\%) & $\begin{array}{c}\text { Loss ratio (\%) } \\
\text { capacity }\end{array}$ \\
\hline I & 817 & 5.06 & 3.25 & 4.71 & 2.06 \\
II & 987 & 4.65 & 6.50 & 5.01 & 0.58 \\
III & 1195 & 3.41 & 5.42 & 6.41 & 2.07 \\
IV & 850 & 5.50 & 4.67 & 4.82 & 5.32 \\
\hline
\end{tabular}

TABLE 4: Normalization of the economic indicators.

\begin{tabular}{lccc}
\hline Scheme & Production capacity $(\mathrm{t} / \mathrm{d})$ & Cost $($ Yuan/t) & Ratio of mined tonnage to development $(\mathrm{m} / \mathrm{kt})$ \\
\hline I & 0.89 & 0.29 & 0.10 \\
II & 0.54 & 0.47 & 0.10 \\
III & 0.10 & 1.00 & 0.40 \\
IV & 1.00 & 0.10 & 0.61 \\
\hline
\end{tabular}


TABLE 5: The corresponding values in vague set theory.

\begin{tabular}{lccc}
\hline Scheme & $t_{i}$ & $f_{i}$ & Vague set \\
\hline I & 0.30 & 0.12 & 0.56 \\
II & 0.27 & 0.18 & 0.58 \\
III & 0.04 & 0.41 & 0.59 \\
IV & 0.40 & 0.17 & 0.68 \\
\hline
\end{tabular}

TABle 6: Comparison of the economic index of before and after the unloading mining.

\begin{tabular}{lcc}
\hline Parameters & Before & After \\
\hline Supporting cost (Yuan/t) & 3.21 & 1.10 \\
Capacity of production (t/d) & 562.00 & 817.00 \\
Dilution ratio (\%) & 5.74 & 4.71 \\
Loss ratio (\%) & 5.61 & 2.06 \\
Ratio of mined tonnage to development $(\mathrm{m} / \mathrm{kt})$ & 8.65 & 3.25 \\
Mining cost (Yuan/t) & 10.21 & 5.06 \\
Maximum principal stress in the stope area $(\mathrm{MPa})$ & 85.67 & 58.28 \\
\hline
\end{tabular}
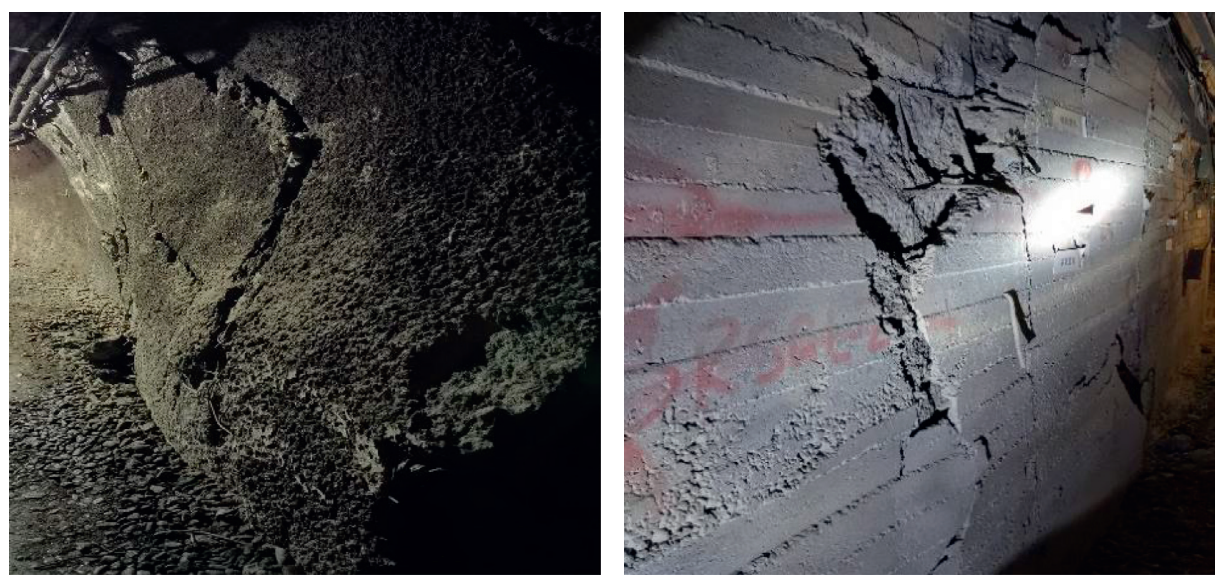

(a)
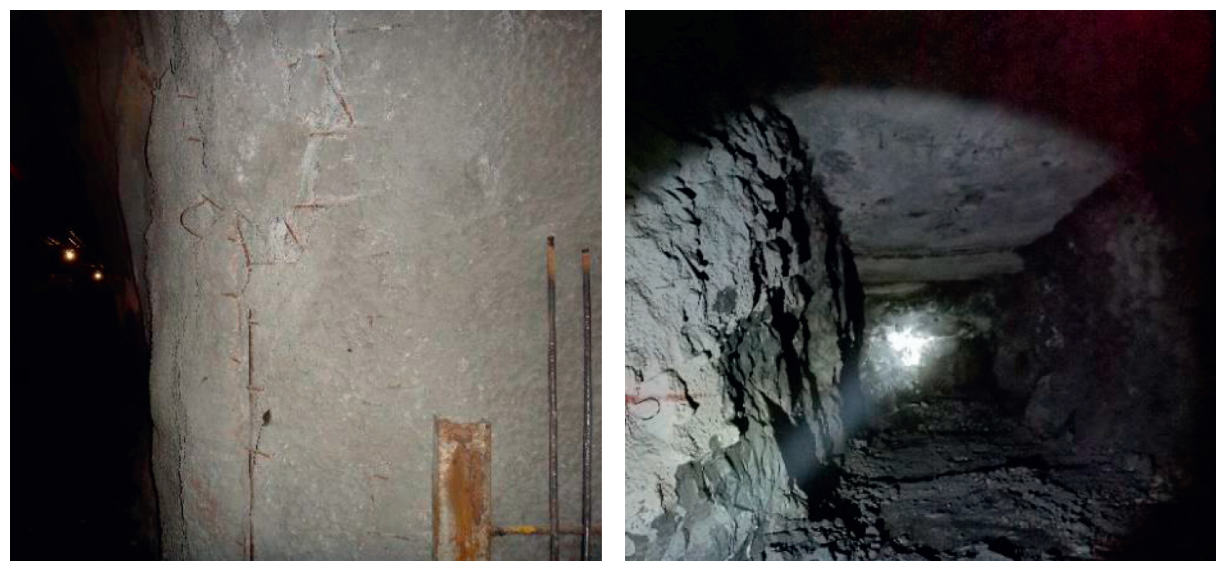

(b)

Figure 9: Failure patterns of the roadway (a) before and (b) after the adopted scheme IV. 
smallest, and the dilution ratio of scheme I is the smallest. In terms of unloading capacity, scheme IV has the largest unloading capacity and scheme III has the worst unloading capacity. It can be seen from the above discussion that the four unloading mining schemes can all achieve good technical production indicators, but the unloading capacity is quite different, and further calculations are needed.

4.4. Determination of Values of Varied Vague Sets. To determine the values of vague sets in varied schemes, we firstly normalized the production capacity, mining cost, and mining-cut ratio. All the results are listed in Table 4 . Then, $t_{i}$ and $f_{i}$ of each scheme according to equations (9) and (10) were calculated. The neutrality $\lambda$ is 0.5 in this calculation. The vague values of each scheme are listed in Table 5.

\section{Results and Discussion}

According to Table 5, it can be seen that the vague value of Scheme IV is the maximum, and the optimal unloading mining scheme is the mining approach with large-section unloading access in the zone. The economic indicators are listed in Table 6. Figure 9 shows the failure patterns of the roadway before and after the proposed approach. Field practice shows that the use of the mining method with largesection unloading (Scheme IV) can release ground pressure in advance, transfer the direction and scope of the ground stress, and compare the actual economic and technical indicators before and after implementation.

According to the results, the calculation results are greatly affected by the method of data standardization, and further research should be carried out from the data processing method to explore the most suitable data processing method of the vague set optimization model. The quantification of unloading capacity may deviate from the actual unloading capacity of the scheme. The calculation results of numerical simulation are based on the assumption of isotropy. For a more realistic response to the actual unloading capacity of the plan, it is recommended to use the in-situ stress data in the actual production process, or to establish a large-scale data model of the whole mine so that the numerical simulation results fit the actual situation. When using this model to select unloading mining schemes, the calculation results are only for reference, and other aspects should be considered in the actual application before making a decision.

\section{Conclusions}

The vague set theory was introduced into the selection of mining methods, and this work establishes a vague set model for deep unloading mining schemes. The following conclusions are achieved:

(1) The vague model of the deep unloading mining scheme was established, and the calculation method of ore production capacity, mining cost, mining-to-cut ratio, dilution ratio, loss ratio, and unloading capacity into $t_{i}$ and $f_{i}$ values was introduced.
(2) The maximum principal stress and stress concentration range of the scheme was compared through numerical simulation, and the unloading coefficient of the scheme was determined. We took the Jinchuan No. 2 mining area as the engineering background and conducted engineering case analysis. Four unloading schemes for deep mining were proposed and compared.

(3) The vague values of four schemes are $0.63,0.45,0.50$, and 0.49 , respectively. According to the vague set value, the optimal unloading mining scheme is chosen to be the mining approach with large-section unloading. The availability and effectiveness of the vague model of the deep unloading mining scheme were finally verified.

\section{Data Availability}

The data used to support the findings of this study are included in the article.

\section{Conflicts of Interest}

The authors declare that there are no conflicts of interest regarding the publication of this paper.

\section{Acknowledgments}

This work was supported by the National Key R\&D Program of China (no. 2017YFC0602900).

\section{References}

[1] D. S. Gu and X. B. Li, Modern Science and Technology of Mining Metal Deposits, Metallurgy Industry Press, Beijing, China, 2006.

[2] F. X. Jiang, X. F. Shi, C. W. Wang et al., "Mechanical mechanism of rock burst accidents in slice mining face under high pressure," Chinese Journal of Geotechnical Engineering, vol. 37, no. 6, pp. 1123-1131, 2015.

[3] B. H. G. Brady and E. T. Brown, Rock Mechanics for Underground Mining, KluwerAcademic Publishers, New York, NY, USA, 3rd edition, 2004.

[4] M. C. He, H. P. Xie, S. P. Peng, and Y. D. Jiang, "Study on rock mechanics in deep mining engineering," Chinese Journal of Rock Mechanics and Engineering, vol. 24, no. 16, pp. 28032813, 2005.

[5] X. T. Feng, S. F. Pei, Q. Jiang, Y. Y. Zhou, S. J. Li, and Z. B. Yao, "Deep fracturing of the hard rock surrounding a large underground cavern subjected to high geostress: in situ observation and mechanism analysis," Rock Mechanics and Rock Engineering, vol. 5, pp. 1-21, 2017.

[6] P. Lin, H. Liu, and W. Zhou, "Experimental study on failure behaviour of deep tunnels under high in-situ stresses," Tunnelling and Underground Space Technology, vol. 46, pp. 28-45, 2015.

[7] H. P. Kang, M. J. Fan, F. Q. Gao, and H. Zhang, "Deformation and support of rock roadway at depth more than 1000 meters," Chinese Journal of Rock Mechanics and Engineering, vol. 34, no. 11, pp. 2227-2241, 2015.

[8] P. Yang, Q. Lei, J. Xiang, J.-P. Latham, and C. Pain, "Numerical simulation of blasting in confined fractured rocks 
using an immersed-body fluid-solid interaction model," Tunnelling and Underground Space Technology, vol. 98, Article ID 103352, 2020.

[9] J. Yu, G. Y. Liu, Y. Y. Cai, J. F. Zhou, S. Y. Liu, and B. X. Tu, "Time-dependent deformation mechanism for swelling softrock tunnels in coal mines and its mathematical deduction," International Journal of Geomechanics, vol. 20, no. 3, Article ID 04019186, 2020.

[10] D. Krantz and T. Scott, Hard-ock Mining: Method SelectionSummary SME Mining Engineering Hand Book, Society of Mining Engineers, vol. 2, pp. 1850-1853, 2nd edition, Karnataka, India, 1992.

[11] M. Cardu, S. Dipietromaria, and P. Oreste, "Sub-level stoping in an underground limestone quarry: an analysis of the state of stress in an evolutionary scenario," Archives of Mining Sciences, vol. 61, no. 1, pp. 199-216, 2016.

[12] B. C. Balusa and A. K. Gorai, "A comparative study of various multi-criteria decision-making models in underground mining method selection," Journal of the Institution of Engineers, vol. 100, no. 1, pp. 1-18, 2019.

[13] W.-Z. Liang, G.-. Zhao, H. Wu, and Y. Chen, "Optimization of mining method in subsea deep gold mines: a case study," Transactions of Nonferrous Metals Society of China, vol. 29, no. 10, pp. 2160-2169, 2019.

[14] H. Ilyes, L. B. Mohamed, M. Chafia, B. Yacine, and K. Ines, "Selection of new appropriate mining method: case of Boukhadra iron ore mine, NE Algeria," Arabian Journal of Geosciences, vol. 12, no. 17, p. 537, 2019.

[15] R. Kant, P. Sen, P. S. Paul, and A. A. Kher, "A review of approaches used for the selection of optimum stope method in hard rock underground mine," International Journal of Applied Engineering Research, vol. 11, no. 11, pp. 0973-4562, 2015.

[16] W.-L. Gau and D. J. Buehrer, "Vague sets," IEEE Transactions on Systems, Man, and Cybernetics, vol. 23, no. 2, pp. 610-614, 1993.

[17] S. M. Chen and J. M. Tan, "Handling multi-criteria fuzzy decision-making problems based on vague set theory," Fuzzy Sets and Systems, vol. 114, no. 1, pp. 103-113, 1994.

[18] K. Kovari, "Erroneous concepts behind the new Austrian tunneling method," Tunnels and Tunneling, vol. 26, no. 11, pp. 38-42, 1994.

[19] C. C. Li, "Rock support design based on the concept of pressure arch," International Journal of Rock Mechanics and Mining Sciences, vol. 43, no. 7, pp. 1083-1090, 2006.

[20] N. Krauland, P. I. Marklund, and M. Board, "Rock support in cutand-fill mining at the Kristineberg mine," in Underground Mining Methods-Engineering Fundamentals and International Case Studies, W. A. Hustrulid and R. L. Bullock, Eds., pp. 325-322, Society for Mining, Metallurgy and Exploration, 2001.

[21] Z. H. Liu, L. S. Yang, X. M. Song, Y. S. Zhao, Z. C. Feng, and D. Yang, "Stress control of deep cutting along roadway over roof rock," Journal of Mining and Safety Engineering, vol. 31, no. 3, pp. 347-353, 2014.

[22] Y. Y. Wang, X. F. Li, and X. D. Li, "Study on stress-relief measures in high-stress zone of deep deposit," Mining and Metallurgical Engineering, vol. 25, no. 4, pp. 4-7, 2005.

[23] Z. Yang, "Key technology research on the efficient exploitation and comprehensive utilization of resources in the deep jinchuan nickel deposit," Engineering, vol. 3, no. 4, pp. 559-566, 2017.

[24] H. Zhao, F. Ma, Y. Zhang, and J. Guo, "Monitoring and mechanisms of ground deformation and ground fissures induced by cut-and-fill mining in the Jinchuan Mine 2, China," Environmental Earth Sciences, vol. 68, no. 7, pp. 1903-1911, 2013. 